\title{
Small-scale variation in sexual size dimorphism and sex ratio in the aquatic moth Acentria ephemerella Denis and Schiffermüller, 1775 (Lepidoptera: Crambidae)
}

\author{
Oliver Miler, ${ }^{\mathrm{a}, \mathrm{c} *}$, Elisabeth M. Gross ${ }^{\mathrm{b}, \mathrm{c}}$ and Dietmar Straile ${ }^{\mathrm{c}}$ \\ ${ }^{a}$ Department of Ecosystem Research, Leibniz Institute of Freshwater Ecology and Inland Fisheries \\ $(I G B)$, Berlin, Germany; ${ }^{b}$ Interdisciplinary Laboratory for Continental Environments (LIEC), \\ Université de Lorraine, Metz, France; ' Limnological Institute, University of Konstanz, Konstanz, \\ Germany
}

\begin{abstract}
The aquatic herbivorous and capital breeding moth Acentria ephemerella Denis and Schiffermüller, 1775 feeds on submerged pondweeds, Potamogeton spp., and is highly preyed upon by fish in the littoral zone. We studied the spatiotemporal within lake variability of length, sexual size dimorphism (SSD) and sex ratio of $A$. ephemerella pupae and of larval population densities. Population densities at three sampling sites strongly increased from July to August and were significantly higher at the Reichenau site in July. Acentria ephemerella sex ratio was male biased at the Güttingen and Hagnau sites, but showed unbiased or slightly biased sex ratios at Reichenau. The SSD was strongly female biased. Female size and SSD declined during summer, possibly due to reduced food quantity/quality. The SSD was highest at Reichenau, with little to no differences between Hagnau and Güttingen. At Reichenau, the high population size in July coincided with an unbiased sex ratio, and large SSD/female size due to multiple, possibly interacting factors, including fish predation.
\end{abstract}

Keywords: Lepidoptera; Acentria ephemerella; life history; population dynamics; sex ratio; sexual size dimorphism

\section{Introduction}

Sexual size dimorphism (SSD) is a common phenomenon in many insect species (Blanckenhorn 2005; Stillwell, Blanckenhorn, Teder, Davidowitz, and Fox 2010; Tammaru, Esperk, Ivanov, and Teder 2010). The ultimate and proximate causes of SSD variability have been studied intensively in the last decade (Stillwell et al. 2010; Tammaru et al. 2010). The SSD shows strong inter- and intra-specific variability largely reflecting different reproductive adaptations of the sexes (Abouheif and Fairbairn 1997; Blanckenhorn et al. 2007; Stillwell et al. 2010; Allen, Zwaan, and Brakefield 2011). The degree and direction of SSD is often caused by sex-specific sensitivity to environmental conditions (Teder and Tammaru 2005; Cox and Calsbeek 2010; Stillwell et al. 2010).

Experimental studies have shown variability in SSD in response to temperature and food quality as characteristic cues of seasonality (Teder and Tammaru 2005; Stillwell and Fox 2007; Stillwell and Davidowitz 2010), and to predation combined with seasonal time constraints (Mikolajewski, Wohlfahrt, Joop, and Beckerman 2013). Several environmental factors can, thus, interact to produce complex SSD patterns (Teder and Tammaru 2005; Stillwell and Fox 2007; Stillwell et al. 2010; Mikolajewski et al. 2013). Predation

*Corresponding author. Email: oliver.miler@web.de 
pressure has been shown to lead to a decreased size at metamorphosis in various arthropod species, such as Ephemeroptera (Scrimgeour and Culp 1994; Peckarsky, Taylor, McIntosh, McPeek, and Lytle 2001; Peckarsky, McIntosh, Taylor, and Dahl 2002; Dahl and Peckarsky 2003) and Odonata (Martin, Johnson, and Moore 1991; Stoks and Cordoba-Aguilar 2012). Similarly, seasonal time constraints can also result in a reduced size at metamorphosis, such as in Lepidoptera (Nylin and Gotthard 1998; Gotthard 2001) and Odonata (Johansson and Rowe 1999; Stoks and Cordoba-Aguilar 2012). Female individuals are often more affected than males by deteriorating food quality/quantity as a result of seasonal time constraints (Teder and Tammaru 2005), due to a high correlation between adult female body size and the number of offspring (and, thus, strong fecundity selection) in many arthropods (Honek 1993; Nylin and Gotthard 1998; Berger, Walters, and Gotthard 2008).

Variability in SSD and size at metamorphosis influences the fecundity and reproductive output of many arthropod taxa (Stillwell et al. 2010; Allen et al. 2011). Fecundity selection on females and sexual selection on males favour larger body sizes (Stillwell et al. 2010). In most arthropod species, females are the larger sex (Teder and Tammaru 2005; Blanckenhorn et al. 2007; Stillwell et al. 2010). In insects, females are often demographically dominant, i.e., female reproductive success is independent of male abundance, but the fecundity of each male is proportional to the abundance of females (Roff 1992; Crowley 2000). Female fecundity can, thus, be derived from body size, and consequently clutch size, as a measure of fecundity, is highly positively correlated with female body size (Honek 1993; McPeek and Peckarsky 1998; Salavert, Zamora-Muñoz, Ruiz-Rodriguez, and Soler 2011). A large male body size is favoured in territorial species and when large nuptial gifts can enhance female fecundity (Crowley and Johansson 2002; Fox, Stillwell, Wallin, and Hitchcock 2006; Stillwell et al. 2010). Accordingly, variability in SSD and size at metamorphosis will strongly influence the reproductive output and population dynamics of arthropods.

In recent years, considerable large-scale within-species variability of SSD with latitude (i.e., temperature) has been demonstrated for arthropods (Blanckenhorn, Stillwell, Young, Fox, and Ashton 2006; Stillwell, Morse, and Fox 2007; Stillwell and Fox 2009). Blanckenhorn et al. (2006) found for the majority of studied vertebrate and invertebrate species that the body size of male individuals changes faster with latitude than that of female individuals. Specimens of the seed-feeding beetle, Stator limbatus Horn, 1873, were smaller, but more sexually dimorphic, with males being larger than females, at lower latitudes, lower seasonality and higher moisture (Stillwell et al. 2007). However, much less is known about small-scale, or local, variability in SSD. Studies analysing small-scale variability of SSD are needed in order to better understand the relative importance of local versus large-scale factors in generating SSD variability.

The lack of knowledge concerning arthropod SSD variability is even more evident in aquatic organisms, especially with respect to field studies. Up to now research on SSD variability has mainly focused on Odonata (Crowley and Johansson 2002; Johansson, Crowley, and Brodin 2005; Mikolajewski, Brodin, Johansson, and Joop 2005; Mikolajewski et al. 2013). Females are larger than males in smaller non-territorial Odonata species with strong selection for female size and, hence, fecundity (Honek 1993; Crowley and Johansson 2002; Johansson et al. 2005). Males in larger territorial species, however, are under strong selection for large body size in order to defend their territories; this results in larger males compared to females (Crowley and Johansson 2002; Johansson et al. 2005). Predation, food availability and photoperiod are major environmental factors influencing SSD variability in Odonata (Mikolajewski et al. 2005, 2013). Odonates have been shown to display 
considerable SSD and sex ratio covariability (Crowley 2000; Crowley and Johansson 2002; Johansson et al. 2005). The larger size of female larvae of non-territorial Odonata has been associated with a highly male-biased sex ratio and a female-biased SSD when considering a constant predation pressure and density-dependent population growth (Crowley 2000; Crowley and Johansson 2002; Johansson et al. 2005). The rationale behind this is that females have a higher foraging activity than males in order to reach a larger size and, therefore, suffer more mortality through predation (Crowley and Johansson 2002). Hence, under predation pressure sex ratio and SSD can be expected to be inversely related (Crowley 2000; Johansson et al. 2005). To a far lesser extent SSD has been studied in aquatic species of other arthropod groups, such as Heteroptera (Nosil 2001), Coleoptera (Fairn, Alarie, and Schulte-Hostedde 2007a, b) and Arachnida (Schütz and Taborsky 2003).

Here, we study the small-scale variability in SSD, size, sex ratio and population size of an aquatic herbivore, Acentria ephemerella Denis and Schiffermüller, 1775 (Lepidoptera: Crambidae). Acentria ephemerella is a semelparous species (capital breeder) with a short adult lifespan ( $<3$ days) and one to three generations per year (Berg 1942; Haenni 1980; Gross, Feldbaum, and Choi 2002; Miler 2009). Densities can increase over several orders of magnitude during the growth period of its food plants, mainly pondweed species (Potamogeton spp.), from June to September (Gross et al. 2002; Miler 2009). All males of the species are macropterous, i.e., develop large and functional wings, whereas the majority of A. ephemerella females are brachypterous, i.e., with only rudimentary wings (Berg 1942). Hence, dispersal via flight is only possible for males and a minority of females. High A. ephemerella population densities result in a strong reduction of food plant biomass, especially of the pondweed Potamogeton perfoliatus L., 1753 (Miler and Straile 2010; Le Bagousse-Pinguet, Gross, and Straile 2012), and consequently a severe food limitation of A. ephemerella (Miler and Straile 2010). However, predation by sticklebacks can decrease A. ephemerella population growth (Miler, Korn, and Straile 2008) and delay plant defoliation. Predation has also been shown to result in male-biased A. ephemerella sex ratios (Miler et al. 2008; Miler 2009). The sex ratio patterns of many terrestrial Lepidoptera species can be influenced by protandry, i.e., the earlier emergence of males before females (Wiklund and Fagerström 1977; Morbey and Ydenberg 2001). Protandry is advantageous for polygynous males, especially if females can only mate once in their lifespan or the offspring quality is highest when mating with virgin females, and if the chance of finding a mate is not limited (Wiklund and Fagerström 1977; Zonneveld and Metz 1991; Wedell 1992). However, protandry has not been reported so far for $A$. ephemerella in the scientific literature, and the short adult lifespan also suggests that it is most likely not an important factor in determining $A$. ephemerella sex ratio bias and SSD (Berg 1942; Gross et al. 2002; Miler 2009).

In summary, a variety of factors such as the limitation of food quality/quantity and predation may influence the SSD of A. ephemerella in situ. The aim of this study is to document small-scale seasonal and spatial variability in SSD, its relationship to sex ratio and to discuss it with respect to environmental factors potentially influencing SSD.

\section{Material and methods}

\section{Study sites and sampling methodology}

Lake Constance, with a surface area of $534 \mathrm{~km}^{2}$ and a maximum depth of $254 \mathrm{~m}$, is the second largest lake in the pre-alpine region of Central Europe $\left(47^{\circ} \mathrm{N}, 09^{\circ} \mathrm{E}\right)$. The Rhine River is the main tributary and flows into the lake at its eastern end. The lake consists of two main basins, Upper Lake Constance and Lower Lake Constance, that are connected 
by a $4 \mathrm{~km}$ long section of the Rhine River and differ strongly in morphology and macrophyte coverage. In the deep Upper Lake Constance $\left(z_{\text {mean }}=101 \mathrm{~m}\right)$, macrophytes grow only in the littoral zones along the steep slopes, whereas they cover wide areas in the shallower Lower Lake Constance $\left(z_{\text {mean }}=13 \mathrm{~m}\right)$ (Schmieder 1997; Wolfer and Straile 2004). We analysed the larval abundances and pupal sex ratio, SSD and size of A. ephemerella at two sites in Upper Lake Constance, Hagnau (H) and Güttingen (G), and one site in Lower Lake Constance, Reichenau (R) (average distance between sites: ca. $16 \mathrm{~km})$.

The main food plants for $A$. ephemerella in Lake Constance are pondweed species Potamogeton spp., especially P. perfoliatus, Potamogeton pectinatus L., 1753, and Potamogeton lucens L., 1753 (Gross et al. 2002). In summer, Myriophyllum spicatum L., 1753 , is less important as a food source for A. ephemerella because it contains polyphenols that act as an anti-herbivore defence (Choi, Bareiss, Walenciak, and Gross 2002; Walenciak, Zwisler, and Gross 2002). However, polyphenols decline in fall in apical shoots, and, thus, larvae eventually feed on M. spicatum when the pondweeds start to die back and, thus, food quality/quantity becomes limiting (Gross et al. 2002). Plant shoots of the pondweed $P$. perfoliatus that were populated by larvae and pupae of $A$. ephemerella were sampled during two sampling periods (13-20 July and 26 July to 3 August 2005). Previous studies have shown that three size cohorts of $A$. ephemerella larvae in Lake Constance coexist simultaneously throughout the season from June to August, thereby indicating three overlapping generations per year (i.e., two with direct development and one with indirect diapause development, see Miler 2009). Other studies have estimated one to three generations per year for A. ephemerella (Berg 1942; Haenni 1980; Gross et al. 2002). Unfortunately, more detailed information concerning important life-history characteristics, such as the exact number of generations per year, sex-specific growth rates and development times of larvae and pupae, and the location of the larval diapause stages, is still lacking, but necessary for a deeper analysis of $A$. ephemerella life-history and population dynamics.

At each sampling site and sampling period, macrophyte samples (5-10 g dry mass each) with attached $A$. ephemerella larvae and pupae were collected at six replicate areas with a sampling area of ca. $5 \mathrm{~m}^{2}$ each. Replicate areas were located at depths between 0.7 and $5.2 \mathrm{~m}$ and had established macrophyte canopies consisting almost exclusively of $P$. perfoliatus with $P$. pectinatus occurring as interspersed specimens or as neighbouring patches (Miler 2009 and personal observation). The density of $A$. ephemerella larvae was calculated as individuals per gram plant dry mass (Ind. $\mathrm{g}^{-1} \mathrm{dm}$ ) for each sample. For the determination of pupal size and sex, replicate samples within each site and sampling period were pooled. All pupae found in the field samples $(n=602)$ were sexed morphologically by measuring and comparing the length of wings and antennae as published in Berg (1942). Pupal size (pupal body length in $\mathrm{mm}$ ) was measured under a stereo microscope (Zeiss Stemi $2000-C$ ) at $10 \times$ to $50 \times$ magnification. For the determination of larval densities and pupal body length, sex ratio and SSD, only living individuals collected in the larval (densities) and pupal (body length, sex ratio and SSD) stages in the field were used. The number of dead pupae was negligible and any dead pupae found in field samples were omitted from the analyses. We did not study the ratio of pupated/emerged individuals here, because it is not possible to specify from the pupal remains in the field when an individual has emerged. Due to their short adult lifespan and different adult habitats (winged terrestrial males and wingless aquatic females, Berg 1942), a quantitative assessment of emerged $A$. ephemerella individuals would not have been possible. SSD was 
estimated according to Lovich and Gibbons (1992) as

$$
\mathrm{SSD}=(\text { size of the larger sex } / \text { size of the smaller sex })-1
$$

In this equation, $A$. ephemerella females were the larger and males the smaller sex. Pupae in an advanced developmental stage (inferred from eye development) already had well-developed eggs, which could be counted after dissection. Clutch size was determined in 60 advanced $A$. ephemerella pupae from a subset of our data at the Güttingen site, sampled at the end of July and at the end of August. In addition, the clutch size of 10 macropterous female pupae, which were available from a different sampling campaign, was determined.

Fish sampling at the three sites was conducted during 2004 at Güttingen (69 sampling units), Hagnau (70 sampling units) and Reichenau (46 sampling units). The reduced number of sampling units at Reichenau in 2004 was due to an earlier seasonal disappearance of macrophyte patches at this site. A second fish sampling campaign took place during 2005, with 23 sampling units each in Güttingen, Hagnau and Reichenau. One fish sampling unit consisted of four minnow traps with two different mesh sizes (fine: $3 \mathrm{~mm}$; coarse: $6 \mathrm{~mm}$ ) and a trap opening diameter of $25 \mathrm{~mm}$. The traps were fixed to a rope and, thus, positioned vertically in the water column via a buoy at the surface and two paving stones as a weight at the bottom of the rope. The traps were placed in the order (from the top) fine-coarse-fine-coarse along the rope. Sampling units were set during daytime within macrophyte patches and were emptied after $24 \mathrm{~h}$.

\section{Statistical analyses}

Analysis of variance (ANOVA) was used to test the effect of sampling period (factor, levels: July, August) and sampling site (factor, levels: Hagnau, Güttingen, Reichenau) on larval density (dependent variable) and pupal size (dependent variable) and the effect of sex (factor, levels: male, female) on pupal size (dependent variable). The effect of sampling site (factor, levels: Hagnau, Güttingen, Reichenau) on stickleback CPUE (dependent variable) was tested with a Kruskal-Wallis test. The effect of sampling period (factor, levels: July, August) on male and female pupal size (dependent variables) at Reichenau was tested with a contrast analysis. We used analysis of covariance (ANCOVA) to analyse the effects of pupal size (covariable) and sampling period (factor, levels: July, August) on clutch size (dependent variable). A logistic regression analysis was used to test for effects of sampling site (factor, levels: Hagnau, Güttingen, Reichenau) and sampling period (factor, levels: July, August) on pupal sex ratio (dependent variable). The 95\% confidence intervals for $\%$ males and for SSD were calculated by nonparametric bootstrap. Statistical analyses were performed using SAS 9.1 (SAS Institute Inc. 2004) and R (R Development Core Team 2011).

\section{Results}

SSD showed a strong seasonal decline at all three sites as well as a high spatial variability (Figure 1(a)). In July, SSD at Reichenau was larger than at the other two sites, while SSD at Hagnau and Güttingen did not differ from each other. SSD in August at Reichenau was larger than at Güttingen, which in turn was larger than at Hagnau. SSD variability strongly mirrored female size variability (Figure 1(a) and 1(b), Table 1). Females were larger and more variable in size than males. However, male size also showed significant 

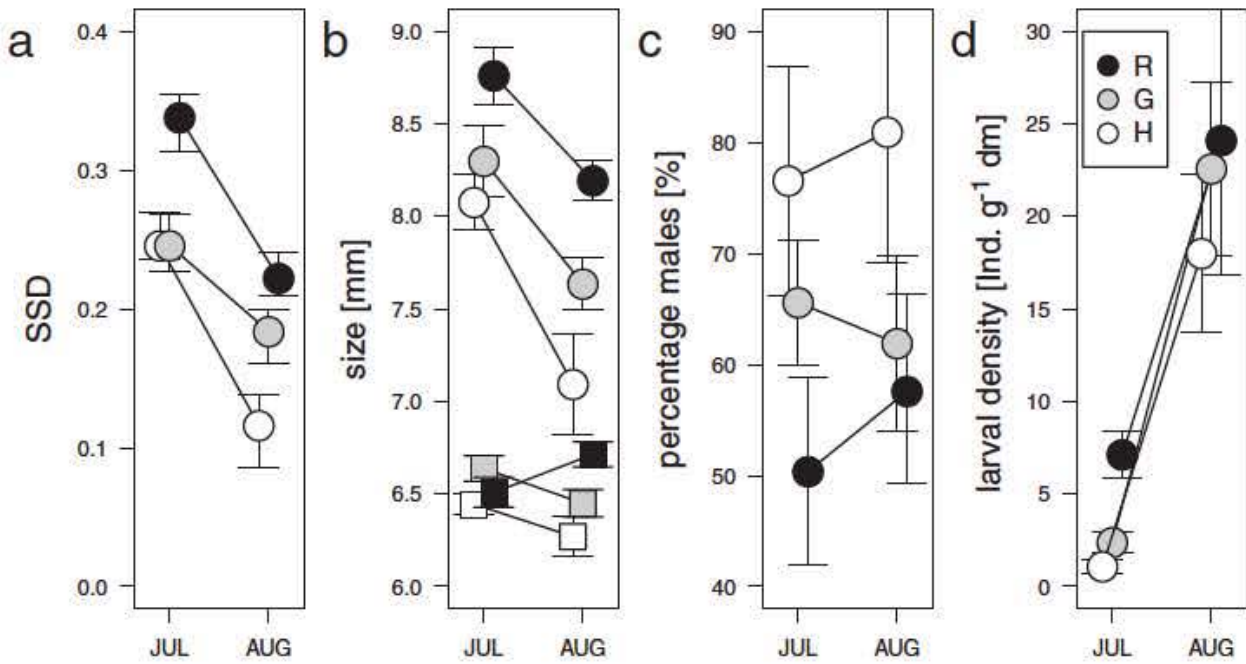

Figure 1. Seasonal changes in mean (a) pupal sexual size dimorphism (SSD), (b) female (circles) and male (squares) pupal size, (c) pupal sex ratio and (d) larval densities of Acentria ephemerella Denis and Schiffermüller, 1775 in Lake Constance at the sampling sites Güttingen (G, grey sym bols), Hagnau (H, white symbols) and Reichenau (R, black symbols) in July and August 2005. Error bars indicate standard errors (population size and pupal size) and $95 \%$ bootstrap confidence inter vals (\% males and SSD).

spatiotemporal variability. In contrast to the other two sites, male size showed a tendency to increase from July towards August at Reichenau (Figure 1(b)). Hence, at Reichenau, the sexes showed opposite size responses to season (contrast analysis, pupal size, comparison between July and August, Reichenau females: $F_{11,501}=9.46, p=0.0022$, Reichenau males: $F_{11}, 501=3.26, p=0.0716$ ). Pupal sex ratio showed striking spatial variability and was not male-biased at Reichenau, whereas a strong male bias was observed at Hagnau ( $>75 \%$ males, Figure 1(c)). At all three sampling sites, the larval densities of $A$. ephemerella increased strongly from July to August, probably due to the successful reproduction of the cohort present in the pupal stage in July. In July, larval densities were higher at Reichenau than at the other two sites (Figure 1(d), Table 1). However, densities did not differ anymore between sites in the second sampling period, presumably because at the end of August, food plants at all three sites were already defoliated and did not allow a further population increase (Figure 1(d), Table 1); densities presumably had reached the carrying capacity at all sites.

Out of 229 female pupae ( 602 pupae in total) found in the samples, only $3(1.3 \%)$ of them were macropterous. Macropterous pupae were found at Güttingen (one) and Reichenau (two) in July. Because the determination of clutch size can only be conducted with pupae in an advanced developmental stage (see the 'Material and methods' section), the clutch size of 10 macropterous female pupae available from a different sampling campaign was determined. Female pupal size was a strong predictor for clutch size and clutch size increased on average by 101 eggs ( \pm 10 eggs) per mm pupal length (Figure 2, $t=$ $9.98, p<0.0001$ ) for brachypterous pupae sampled in July and August and for macropterous pupae. There was no evidence for differing clutch size-body size slopes between these three groups (ANCOVA, $p>0.05$ ). After accounting for body size, clutch size was highest for brachypterous pupae in July samples (95 eggs \pm 14 eggs SE, $t=6.99, p<$ 0.0001 ), slightly but significantly lower for brachypterous pupae sampled in August 
Table 1. Results of statistical tests analysing spatiotemporal variability in Acentria ephemerella Denis and Schiffermüller, 1775 larval population density, pupal sex ratio, and size of female and male pupae. ANOVA was used to test for differences in larval population density and pupal sizes. Logistic regression was used to test for differences in pupal sex ratio between sites and sampling periods.

\begin{tabular}{lccc}
\hline & df & Test statistic & $p$ value \\
\hline Larval population density & & & \\
Site & 2 & 14.44 & $<0.0001$ \\
Period & 1 & 2.58 & 0.12 \\
Site ${ }^{*}$ Period & 2 & 3.76 & 0.03 \\
Pupal sex ratio & & & \\
Site & 2 & 17.4 & 0.0002 \\
Period & 1 & 0.35 & 0.55 \\
Pupal size & & & \\
Site & 2 & 20.58 & $<0.0001$ \\
Period & 1 & 27.46 & $<0.0001$ \\
Sex & 1 & 431.24 & $<0.0001$ \\
Site ${ }^{*}$ Period & 2 & 3.46 & 0.03 \\
Period ${ }^{*}$ Sex & 1 & 19.2 & $<0.0001$ \\
Site ${ }^{*}$ Sex & 2 & 5.69 & 0.004 \\
Site $^{*}$ Period ${ }^{*}$ Sex & 2 & 0.69 & 0.5 \\
\hline
\end{tabular}

(92 eggs \pm 12 eggs SE, $t=7.59, p<0.0001)$ and considerably lower for macropterous pupae (36 eggs \pm 15 eggs SE, $t=2.42, p=0.0416$ ).

With 276 minnow traps employed at Reichenau, we did not catch a single stickleback in 2004 (184 minnow traps) nor in 2005 (92 minnow traps). In contrast, we caught 13 sticklebacks at Güttingen ( 276 minnow traps) and 46 at Hagnau ( 280 minnow traps) in

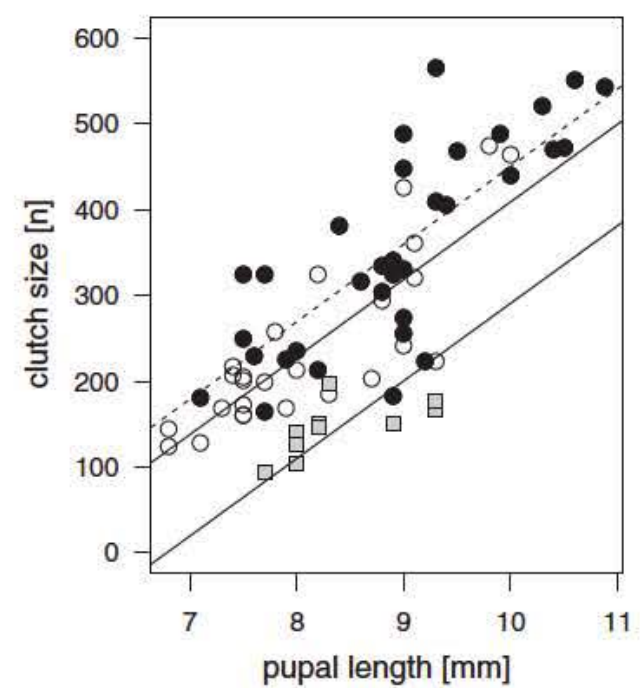

Figure 2. Relationship between body length of brachypterous female pupae of Acentria ephemer ella Denis and Schiffermüller, 1775 (in $\mathrm{mm}$ ) and clutch size (i.e., the number of eggs) in July (white circles) and August (black circles) and of macropterous female pupae in July (grey squares). 
2004, and 19 sticklebacks at Güttingen (92 minnow traps) and 3 at Hagnau (92 minnow traps) in 2005. A Kruskal-Wallis test indicated significant differences in catches between sampling sites $\left(F_{2,251}=6.25, p=0.0022\right)$.

\section{Discussion}

Our data suggest spatial co-variability between population characteristics of A. ephemerella in the July samples; larval densities were largest at Reichenau, medium at Güttingen and lowest at Hagnau. Female pupal size and SSD were highest at Reichenau with little to no differences between Hagnau and Güttingen (Figure 1(a) and 1(b)), and the sex ratio bias (\% males) was lower at Reichenau compared to Güttingen and Hagnau. Hence, a higher population size at Reichenau coincided with an unbiased sex ratio, large females and large SSD. In August, the ranking of sites with respect to SSD and sex ratio bias persisted; however, population densities did not differ between sites. The cause for this is presumably strong population growth, since $A$. ephemerella densities had reached carrying capacity, and high within-site variability (Figure 1(d)).

Co-variation between SSD and sex ratio, i.e., a sex ratio bias at maturation towards the sex with the smaller adult body size, has been predicted to arise for semelparous species when survival costs to achieve a large size exist (Crowley 2000). This prediction is generally supported for A. ephemerella; at maturation the smaller sex (male) dominates (Miler et al. 2008). However, between-site co-variability is contrary to the predictions of Crowley (2000), since the largest size difference between sexes in our study was associated with the lowest sex ratio bias. An explanation for the differences in patterns of covariability between SSD and sex ratio could be that Crowley (2000) and Johansson et al. (2005) studied the effects of different larval activity patterns (which are assumed to determine predation pressure) on SSD and sex ratio. However, in our study predation pressure was most likely not only determined by larval activity, but also by differences in predator density between sites; we found higher stickleback CPUE at Hagnau and Güttingen, compared to Reichenau (see the 'Results' section). Low predation pressure, i.e., small survival costs to achieve a large body size at Reichenau, might have resulted in an unbiased sex ratio and large females (a large SSD), whereas higher predation pressure at other sites might have caused male-biased sex ratios and metamorphosis at a smaller size of females due to phenotypic plasticity.

Adaptive phenotypic plasticity in insect body size in response to predator kairomones is well known (Peckarsky et al. 2002; Benard 2004; Mikolajewski et al. 2013). However, differential responses to predation as a cause for changes in insect SSD seem not to have yet received much attention and a recent review lists larval density, temperature, photoperiod and diet quantity/quality, but not predation as important environmental factors influencing sex-specific plasticity of insect body sizes (Stillwell et al. 2010; but see Mikolajewski et al. 2013). Experimental and field studies assessing the effects of predation on the combined variability of SSD and sex ratio are urgently necessary to widen the focus from the Odonata studied by Crowley (2000) and Crowley and Johansson (2002) to other (aquatic) insect orders.

Among the factors often associated with body size and SSD variability (Stillwell et al. 2010), both temperature and food quantity/quality are unlikely to be the reason for the spatial variability observed in this study. Because Lower Lake Constance is shallower, temperatures were slightly higher at Reichenau than at the other two sites (IGKB 2006). Food quantity and quality were lowest at Reichenau, as even upper leaves were heavily grazed and started to decay (personal observation). This might be because densities of 
A. ephemerella larvae were highest at this site, which is in line with experimental findings: Acentria ephemerella herbivory has been shown to affect the quantity and quality of P. perfoliatus, its main food plant in Lake Constance (Miler 2009; Miler and Straile 2010). Potamogeton perfoliatus specimens that are grazed upon by $A$. ephemerella larvae show an earlier senescence and a reduced amount of above- and below-ground biomass at the end of the vegetation period compared to the control treatment with no larvae (Miler and Straile 2010). Furthermore, increased grazing pressure (higher A. ephemerella larval densities) strongly reduces the above-ground biomass of $P$. perfoliatus (Le Bagousse-Pinguet et al. 2012). High temperatures and low food quantity/quality have been shown to cause maturation at a smaller size in ectothermic animals (Berrigan and Charnov 1994; Stillwell et al. 2007). If temperature and food plant quantity/quality are causal for the observed spatial variability in size at metamorphosis and SSD, we would expect the smallest size at metamorphosis to occur at Reichenau. However, the opposite was true; female pupae at the Reichenau site were the largest of all sites.

A pupal sex ratio bias might also be caused by differences in development time between sexes. Protandry is a common phenomenon in many moths and butterflies and can be achieved either by a shorter development time of males or a higher growth rate of males compared with females (Wiklund, Nylin, and Forsberg 1991; Zijlstra, Kesbeke, Zwaan, and Brakefield 2002; Allen et al. 2011). Faster development and earlier pupation of males should lead to male-biased pupal sex ratios shortly after male larvae start to pupate. However, because of earlier metamorphosis (emergence) of males, protandry should also result in female-biased sex ratios when the first male pupae - but not yet the female pupae - start to emerge. Consequently, if there is protandry in the population, we should expect both male and female bias of $A$. ephemerella pupal sex ratios to occur. However, during six consecutive study years (2002-2007), we never observed a female bias, but always a male bias in pupal sex ratios (this study; Miler et al. 2008). Consequently, differences in development time between male and female A. ephemerella are not likely the explanation for the observed male bias in pupal sex ratios.

Hence, our field data are more consistent with the hypothesis that spatial differences in predation pressure are responsible for the observed differences in A. ephemerella population characteristics, including SSD. This suggests that more emphasis should be put on predation as an important factor influencing SSD of other insect species at least with respect to small-scale spatial SSD variability.

In contrast to its spatial variability, the temporal variability of SSD may be due to a reduced food quantity and quality induced by increasing herbivory due to the increasing population size of $A$. ephemerella larvae (Figure 1(d); Miler and Straile 2010; Le Bagousse-Pinguet et al. 2012; Fornoff and Gross 2014). The high larval densities reached by $A$. ephemerella in this study in August 2005 are higher than the highest previously found for $A$. ephemerella during summer on $P$. perfoliatus, with $7.2 \pm 0.7$ Ind. $\mathrm{g}^{-1} \mathrm{dm}$ (August 2000; Gross et al. 2002). High densities of $A$. ephemerella larvae, up to 20 Ind. $\mathrm{g}^{-1} \mathrm{dm}$, have been shown in experiments to strongly decrease the quality/quantity of P. perfoliatus shoots (Miler and Straile 2010; Le Bagousse-Pinguet et al. 2012). Diet has been shown to shift SSD in various insect species since adult females are more dependent on nutrients of limited availability (e.g., nitrogen) than males and they are in general more sensitive to deteriorating environmental conditions late in the growth season (Teder and Tammaru 2005). Hence, deteriorating food conditions are a plausible cause for a reduction of female body size and consequently SSD and clutch size from July to August (Table 1, Figures 1(a), 1(b) and 2). Here, macropterous pupae were overall less fertile than brachypterous ones (Figure 2), constituting a possible evolutionary reason for the 
origin of brachyptery. Altogether, this suggests that different factors might be responsible for spatial versus temporal variability of SSD in A. ephemerella.

We expect the spatiotemporal variability of different life-history characteristics of A. ephemerella to interact and result in combined effects on local population dynamics. A higher male bias in pupal sex ratio and a smaller female size of pupae at Hagnau compared to Reichenau has probably affected population growth of $A$. ephemerella in two ways. Assuming the pupal size-clutch size relationship in Figure 2 holds true for all sites, smaller pupae at Hagnau have smaller clutches, potentially leading to a lower reproductive output at Hagnau compared to Reichenau (Figure 1(b)). As in the Hagnau population there was also a lower density of female relative to male pupae than in the Reichenau population (Figure 1(c)), the difference in reproductive output between these two sites increased further.

\section{Conclusions}

In summary, our study suggests the presence of small-scale, within-lake variability in aquatic insect SSD, female size, sex ratio bias and population density. Deteriorating food conditions might have caused the reduction of female body size and consequently SSD and clutch size from July to August. Acentria ephemerella pupal sex ratio was malebiased at Güttingen and Hagnau, but showed unbiased or slightly male-biased sex ratios at Reichenau. SSD as well as female pupal size was highest at Reichenau, with little to no differences between Hagnau and Güttingen. Hence, at Reichenau, a high population size in July coincided with unbiased sex ratios and a large SSD/female pupal size. This combination of spatial life-history characteristics is probably due to multiple, possibly interacting factors. Field densities of benthivorous sticklebacks and experimental evidence indicate that fish predation might play a major role because stickleback predation pressure has been shown to lead to a male-biased sex ratio and reduced SSD/female pupal size (Miler et al. 2008), as it is the case in Güttingen and especially Hagnau. Clearly, more experimental work is needed to disentangle the effects of the different environmental factors on SSD and sex ratio in this system.

\section{Acknowledgements}

We thank Martin Wolf for technical assistance and Gisela Richter for the processing of plant sam ples. We thank Dirk Mikolajewski and two anonymous reviewers for helpful comments that signifi cantly improved the content of our manuscript. Many students and colleagues assisted in the field work and the subsequent processing of plant and invertebrate samples: Robin Assfalg, Martin Ben zler, Konrad Bergen, Christoph Berron, Jens Bierfeld, Marc Hamitou, Marion Jetter, and Stanley Lau. We greatly appreciate revision of the English by Ray Newman.

\section{Disclosure statement}

No potential conflict of interest was reported by the authors.

\section{Funding}

This research project was part of the Collaborative Research Center (CRC) no. 454 'Littoral of Lake Constance' and was financially supported by the Deutsche Forschungsgemeinschaft (DFG). 


\section{References}

Abouheif, E., and Fairbairn, D.J. (1997), 'A Comparative Analysis of Allometry for Sexual Size Dimorphism: Assessing Rensch's Rule’, American Naturalist, 149, 540562.

Allen, C.E., Zwaan, B.J., and Brakefield, P.M. (2011), 'Evolution of Sexual Dimorphism in the Lepidoptera', Annual Review of Entomology, 56, 445464.

Benard, M.F. (2004), 'Predator Induced Phenotypic Plasticity in Organisms with Complex Life Histories', Annual Review of Ecology and Systematics, 35, 651673.

Berg, K. (1942), 'Contributions to the Biology of the Aquatic Moth Acentropus niveus (Oliv.)', Videnskabelige Meddelelser fra Dansk Naturhistorisk Forening i Kjøbenhavn, 105, 59139.

Berger, D., Walters, R., and Gotthard, K. (2008), 'What Limits Insect Fecundity? Body Size and Temperature dependent Egg Maturation and Oviposition in a Butterfly', Functional Ecology, $22,523529$.

Berrigan, D., and Charnov, E.L. (1994), 'Reaction Norms for Age and Size at Maturity in Response to Temperature: A Puzzle for Life Historians', Oikos, 70, 474478.

Blanckenhorn, W.U. (2005), 'Behavioral Causes and Consequences of Sexual Size Dimorphism', Ethology, 111, 9771016.

Blanckenhorn, W.U., Dixon, A.F.G., Fairbairn, D.J., Foellmer, M.W., Gibert, P., van der Linde, K., Meier, R., Nylin, S., Pitnick, S., Schoff, C., Signorelli, M., Teder, T., and Wiklund, C. (2007), 'Proximate Causes of Rensch's Rule: Does Sexual Size Dimorphism in Arthropods Result from Sex Differences in Development Time?', American Naturalist, 169, 245257.

Blanckenhorn, W.U., Stillwell, R.C., Young, K.A., Fox, C.W., and Ashton, K.G. (2006), 'When Rensch Meets Bergmann: Does Sexual Dimorphism Change Systematically with Latitude?', Evolution, 60, 20042011.

Choi, C., Bareiss, C., Walenciak, O., and Gross, E.M. (2002), 'Impact of Polyphenols on the Growth of the Aquatic Herbivore Acentria ephemerella (Lepidoptera: Pyralidae)', Journal of Chemical Ecology, 28, 22232235.

Cox, R.M., and Calsbeek, R. (2010), 'Sex Specific Selection and Intraspecific Variation in Sexual Size Dimorphism', Evolution, 64, 798809.

Crowley, P.H. (2000), 'Sexual Dimorphism with Female Demographic Dominance: Age, Size, and Sex Ratio at Maturation', Ecology, 81, 25922605.

Crowley, P.H., and Johansson, F. (2002), 'Sexual Dimorphism in Odonata: Age, Size and Sex Ratio at Emergence', Oikos, 96, 364378 .

Dahl, J., and Peckarsky, B.L. (2003), 'Developmental Responses to Predation Risk in Morphologi cally Defended Mayflies', Oecologia, 137, 188194.

Denis, J.N.C.M., and Schiffermüller, I. (1775), Systematisches Verzeichnis der Schmetterlinge der Wienergegend, herausgegeben von einigen Lehrern am $k$. $k$. Theresianum, Vienna: A. Bernardt.

Fairn, E., Alarie, Y., and Schulte Hostedde, A. (2007a), 'Sexual Size Dimorphism in the Diving Beetle Laccophilus maculosus Say (Coleoptera: Dytiscidae)', The Coleopterists Bulletin, 61, 409418.

Fairn, E., Alarie, Y., and Schulte Hostedde, A. (2007b), 'Sexual Size and Shape Dimorphism in Dineutus nigrior (Coleoptera: Gyrinidae)’, The Coleopterists Bulletin, 61, 113120.

Fornoff, F., and Gross, E. (2014), 'Induced Defense Mechanisms in an Aquatic Angiosperm to Insect Herbivory', Oecologia, 175, 173185.

Fox, C.W., Stillwell, R.C., Wallin, W.G., and Hitchcock, L.J. (2006), 'Temperature and Host Spe cies Affect Nuptial Gift Size in a Seed Feeding Beetle', Functional Ecology, 20, 10031011.

Gotthard, K., 2001, 'Growth Strategies of Ectothermic Animals in Temperate Environments', in Animal Developmental Ecology, eds. D. Atkinson and M. Thorndyke, Oxford: BIOS Scientific Publishers Ltd, pp. 118.

Gross, E.M., Feldbaum, C., and Choi, C. (2002), 'High Abundance of Herbivorous Lepidoptera Lar vae (Acentria ephemerella DENIS \& SCHIFFERMULLER) on Submersed Macrophytes in Lake Constance (Germany)', Archiv für Hydrobiologie, 155, 121.

Haenni, J.P. (1980), 'Contribution à la Connaissance de la Biologie des Papillons Aquatiques (Lepi doptera, Pyraloidea) sur la Rive sud du Lac de Neuchâtel', Bulletin de la Société des science naturelles de Neuchâtel, 103, 2943.

Honek, A. (1993), 'Intraspecific Variation in Body Size and Fecundity in Insects: A General Relationship', Oikos, 66, 483492.

IGKB (2006), 'Limnologischer Zustand des Bodensees, Januar 2005 bis März 2006', Jahresbericht Internationale Gewässerschutzkommission des Bodensees, 33, 183. 
Johansson, F., Crowley, P.H., and Brodin, T. (2005), 'Sexual Size Dimorphism and Sex Ratios in Dragonflies (Odonata)', Biological Journal of the Linnean Society, 86, 507513.

Johansson, F., and Rowe, L. (1999), 'Life History and Behavioral Responses to Time Constraints in a Damselfly', Ecology, 80, 12421252.

Le Bagousse Pinguet, Y., Gross, E., and Straile, D. (2012), 'Release from Competition and Protec tion Determine the Outcome of Plant Interactions Along a Grazing Gradient', Oikos, 121, 95101

Lovich, J.E., and Gibbons, J.W. (1992), 'A Review of Techniques for Quantifying Sexual Size Dimorphism', Growth, Development, and Aging, 56, 269281.

Martin, T.H., Johnson, D.M., and Moore, R.D. (1991), 'Fish Mediated Alternative Life History Strategies in the Dragonfly Epitheca cynosure', Journal of the North American Benthological Society, 10, 271279.

McPeek, M.A., and Peckarsky, B.L. (1998), 'Life Histories and the Strengths of Species Interac tions: Combining Mortality, Growth, and Fecundity Effects', Ecology, 79, 867879.

Mikolajewski, D.J., Brodin, T., Johansson, F., and Joop, G. (2005), 'Phenotypic Plasticity in Gender Specific Life history: Effects of Food Availability and Predation', Oikos, 110, 91100.

Mikolajewski, D.J., Wohlfahrt, B., Joop, G., and Beckerman, A.P. (2013), 'Sexual Size Dimorphism and the Integration of Phenotypically Plastic Traits', Ecological Entomology, 38, 418428.

Miler, O. (2009), 'The Aquatic Moth Acentria Ephemerella as a Key Species in Submerged Aquatic Vegetation Direct and Trait Mediated Interactions with Predators and Food Plants', PhD dis sertation, published online, University of Konstanz, Konstanz. http://nbn resolving.de/urn:nbn: de:bsz:352 opus 80747

Miler, O., Korn, M., and Straile, D. (2008), 'Experimental Evidence for a Strong Influence of Stick leback Predation on the Population Dynamics and Sex Ratio of an Aquatic Moth', Fundamental and Applied Limnology, 173, 187196.

Miler, O., and Straile, D. (2010), 'How to Cope with a Superior Enemy? Plant Defence Strategies in Response to Annual Herbivore Outbreaks', Journal of Ecology, 98, 900907.

Morbey, Y.E., and Ydenberg, R.C. (2001), 'Protandrous Arrival Timing to Breeding Areas: A Review', Ecology Letters, 4, 663673.

Nosil, P. (2001), 'Sexual Size Dimorphism in a Natural Population of Callicorixa vulnerata (Hemi ptera: Corixidae)', The Canadian Entomologist, 133, 311313.

Nylin, S., and Gotthard, K. (1998), 'Plasticity in Life history Traits', Annual Review of Entomology, 43,6383

Peckarsky, B.L., McIntosh, A.R., Taylor, B.W., and Dahl, J. (2002), 'Predator Chemicals Induce Changes in Mayfly Life History Traits: A Whole Stream Manipulation', Ecology, 83, 612618.

Peckarsky, B.L., Taylor, B.W., McIntosh, A.R., McPeek, M.A., and Lytle, D.A. (2001), 'Variation in Mayfly Size at Metamorphosis as a Developmental Response to Risk of Predation', Ecology, $82,740757$.

R Development Core Team (2011), R: A Language and Environment for Statistical Computing, Vienna: R Foundation for Statistical Computing. ISBN: 390005107 0. http://www.R project. org/

Roff, D.A. (1992), The Evolution of Life Histories: Theory and Analysis, New York, NY: Chapman and Hall.

Salavert, V., Zamora Muñoz, C., Ruiz Rodriguez, M., and Soler, J. (2011), 'Female Biased Size Dimorphism in a Diapausing Caddisfly, Mesophylax aspersus: Effect of Fecundity and Natural and Sexual Selection', Ecological Entomology, 36, 389395.

SAS Institute Inc. (2004), SAS Software, Version 9.1, Cary, NC: SAS Institute Inc.

Schmieder, K. (1997), 'Littoral Zone GIS of Lake Constance: A Useful Tool in Lake Monitoring and Autecological Studies with Submersed Macrophytes', Aquatic Botany, 58, 333346.

Schütz, D., and Taborsky, M. (2003), 'Adaptations to an Aquatic Life May be Responsible for the Reversed Sexual Size Dimorphism in the Water Spider, Argyroneta aquatica', Evolutionary Ecology Research, 5, 105117.

Scrimgeour, G.J., and Culp, J.M. (1994), 'Feeding While Evading Predators by a Lotic Mayfly: Linking Short term Foraging Behaviours to Long term Fitness Consequences', Oecologia, 100, 128134.

Stillwell, R., Blanckenhorn, W.U., Teder, T., Davidowitz, G., and Fox, C.W. (2010), 'Sex Differen ces in Phenotypic Plasticity Affect Variation in Sexual Size Dimorphism in Insects: From Phys iology to Evolution', Annual Review of Entomology, 55, 227245. 
Stillwell, R.C., and Davidowitz, G. (2010), 'Sex Differences in Phenotypic Plasticity of a Mecha nism that Controls Body Size: Implications for Sexual Size Dimorphism', Proceedings of the Royal Society, B: Biological Sciences, 277, 38193826.

Stillwell, R.C., and Fox, C.W. (2007), 'Environmental Effects on Sexual Size Dimorphism of a Seed Feeding Beetle', Oecologia, 153, 27380.

Stillwell, R.C., and Fox, C.W. (2009), 'Geographical Variation in Body Size, Sexual Size Dimor phism and Fitness Components of a Seed Beetle: Local Adaptation Versus Phenotypic Plasti city', Oikos, 118, 703712.

Stillwell, R.C., Morse, G.E., and Fox, C.W. (2007), 'Geographic Variation in Body Size and Sexual Size Dimorphism of a Seed Feeding Beetle', American Naturalist, 170, 358369.

Stoks, R., and Cordoba Aguilar, A. (2012), 'Evolutionary Ecology of Odonata: A Complex Life Cycle Perspective', Annual Review of Entomology, 57, 249265.

Tammaru, T., Esperk, T., Ivanov, V., and Teder, T. (2010), 'Proximate Sources of Sexual Size Dimorphism in Insects: Locating Constraints on Larval Growth Schedules', Evolutionary Ecol ogy, 24, 161175.

Teder, T., and Tammaru, T. (2005), 'Sexual Size Dimorphism Within Species Increases with Body Size in Insects', Oikos, 108, 321334.

Walenciak, O., Zwisler, W., and Gross, E.M. (2002), 'Influence of Myriophyllum spicatum Derived Tannins on Gut Microbiota of its Herbivore Acentria ephemerella (Lepidoptera: Pyralidae)', Journal of Chemical Ecology, 28, 20252036.

Wedell, N. (1992), 'Protandry and Mate Assessment in the Wartbiter Decticus Verrucivorus (Orthoptera: Tettigoniidae)', Behavioral Ecology and Sociobiology, 31, 301308.

Wiklund, C., and Fagerström, T. (1977), 'Why do Males Emerge Before Females? A Hypothesis to Explain the Incidence of Protandry in Butterflies', Oecologia, 31, 153158.

Wiklund, C., Nylin, S., and Forsberg, J. (1991), 'Sex Related Variation in Growth Rate as a Result of Selection for Large Size and Protandry in a Bivoltine Butterfly, Pieris napi', Oikos, 60, 241250.

Wolfer, S., and Straile, D. (2004), 'Spatial and Temporal Dynamics of Clonal Architecture in Pota mogeton perfoliatus L.', Aquatic Botany, 78, 307318.

Zijlstra, W.G., Kesbeke, F., Zwaan, B.J., and Brakefield, P.M. (2002), 'Protandry in the Butterfly Bicyclus anynana', Evolutionary Ecology Research, 4, 12291240.

Zonneveld, C., and Metz, J.A.J. (1991), 'Models on Butterfly Protandry: Virgin Females Are at Risk to Die', Theoretical Population Biology, 40, 308321. 